\title{
Effect of smoking on pleural thickening in asbestos workers
}

\author{
Eiji Yano, Kozo Tanaka, Makoto Funaki, Kazuko Maeda, Chiaki Matsunaga, Kazue Yamaoka
}

\begin{abstract}
It is well known that an interaction exists between smoking and exposure to asbestos in the occurrence of lung cancer, whereas occurrence of malignant mesothelioma has not been related to smoking. In the case of pleural thickening related to asbestos, there is a disagreement in previous studies as to the effect of smoking. This could be because the diagnosis of pleural changes has a subjective element. Taking this into account, in the present work the maximum width of the pleura was used as an index of pleural changes. Study subjects were 134 asbestos workers of a brake manufacturing company who had received medical checks in 1978 and in 1990. The maximum width of the pleura on the chest $x$ ray films of the workers was measured by two examiners who did not know the year of examination or smoking state of the worker. A general linear model was applied to analyse the effects of smoking, the year of examination, age, and duration of exposure to asbestos. The difference between maximum widths measured in 1978 and 1990 suggested chronological progression. The increase in width during the 12 years, however, did not differ significantly between smokers and nonsmokers. This suggests that smoking does not significantly increase pleural thickening in asbestos workers.
\end{abstract}

(British fournal of Industrial Medicine 1993;50:898-901)

Teikyo University School of Medicine, Tokyo, Japan E Yano

The University of Tokyo, Faculty of Medicine, Tokyo, Japan

K Tanaka, M Funaki

Musashigaoka College, Saitama, Japan

K Maeda

Industrial Health Center of Saitama, Saitama, Japan

C Matsunaga

Teikyo University School of Jurisprudence, Tokyo, Japan

K Yamaoka
It is generally known that exposure to asbestos causes various lesions. Among them are lung cancer, malignant mesothelioma, asbestosis, and pleural thickening. It is believed that exposure to asbestos and smoking have a synergistic effect on the incidence of lung cancer. For instance, Selikoff et al $^{1}$ reported that the relative risk of lung cancer in asbestos workers increased six to 10-fold and in heavy smokers who were asbestos workers it increased by 92 -fold. The question naturally arises as to whether or not exposure to asbestos and smoking also have interactions on other asbestos related respiratory diseases.

For malignant mesothelioma, the possibility of a synergistic effect between exposure to asbestos and smoking has been rejected by Elmes. ${ }^{2}$ Weiss $e^{2} a^{3}$ concluded from the results of 11 cross sectional studies and seven cohort studies that the risk of asbestosis is increased in smokers. Also, other reports support the relation between smoking and asbestosis..$^{4-6}$

On the other hand, reports on non-malignant pleural changes are not in agreement. Harries $\mathrm{et}^{\mathrm{al}}{ }^{7}$ examined 23340 shipyard employees and found that the prevalence of pleural changes was higher in smokers than in non-smokers. Andrion et $a l^{8}$ reported the results of 898 necropsies. Of 86 men (aged 50 years or older) exposed to asbestos, pleural plaques were found in 42 of 68 smokers and in four of 18 non-smokers. The difference was statistically significant. According to Kasuga et $a^{5}$ the prevalence of pleural changes in 184 workers exposed to asbestos for 10 years or longer was nine of 31 non-smokers, 20 of 53 medium degree smokers (Brinkman index <400), and 40 of 100 heavy smokers (Brinkman Index $\geqslant 400$ ), but the difference was not statistically significant. Rosenstock et $a^{6}{ }^{6}$ stratified 684 asbestos workers by age and classified their degree of smoking for five age groups. Their results indicated no relation between smoking and pleural thickening. Thus there is still no conclusion concerning the difference of pleural thickening between smokers and non-smokers who are exposed to asbestos.

One of the reasons for the disagreement is the lack of uniformity in evaluation, which is often 
Table 1 Characteristics of the study population (as of 1990).

\begin{tabular}{|c|c|c|c|c|}
\hline & $\begin{array}{l}\text { No } \\
\text { of } \\
\text { subjects }\end{array}$ & $\begin{array}{l}\text { Age }(y) \\
\text { Mean (SD) }\end{array}$ & $\begin{array}{l}\text { Duration of } \\
\text { exposure } \\
\text { to asbestos }(y r)^{+} \\
\text {Mean (SD) }\end{array}$ & $\begin{array}{l}\text { Brinkman } \\
\text { index } \star \star \star \\
\text { Mean (SD) }\end{array}$ \\
\hline $\begin{array}{l}\text { Non-smokers } \\
\text { Ex-smokers } \\
\text { Current }\end{array}$ & $\begin{array}{l}20 \\
29\end{array}$ & $\begin{array}{l}44 \cdot 3(7 \cdot 1) \\
46 \cdot 4(8 \cdot 3)\end{array}$ & $\begin{array}{l}22.8(7 \cdot 3) \\
23.3(9 \cdot 0)\end{array}$ & $\begin{array}{l}0 \\
256 \cdot 7(249 \cdot 3)\end{array}$ \\
\hline smokers & 78 & $45 \cdot 7(6 \cdot 2)$ & $24 \cdot 8(7 \cdot 6)$ & $505 \cdot 6(155 \cdot 8)$ \\
\hline
\end{tabular}

$\star \star \star=\mathrm{p}<0.001$.

†Difference over the smoking status categories was not statistically significant.

subjective. Also, these results are based on evaluations made at a single point in time and not on long term studies. To avoid these errors, we used pleural thickening in $x$ ray films as an index, so that judgements were less subjective and were measured chronologically without the knowledge of smoking state and the year of examination. Results were then classified and compared. Based on these results, the difference of the pleural thickness between smokers and non-smokers was studied.

\section{Subjects and methods}

STUDY SUBJECTS

Four hundred and ninety workers handling asbestos at a brake manufacturing company and at its subcontracting company received a medical checkup in April 1978. It was based on the Ordinance for Prevention of Hazards for Specified Chemical Substances, which requires chest radiographs for all asbestos workers at intervals of six months. Of these workers, 146 received another medical check up in the spring of 1990 . Of these 146 workers, six women, who were non-smokers and six men, whose smoking state was uncertain or unstable, were excluded. The remaining 134 men were used as study subjects. Two chest $x$ ray films taken at an interval of 12 years for each subject were used for analysis. Both lungs were examined.

\section{MEASUREMENT OF PLEURAL THICKNESS AND EVALUATION OF PLEURAL THICKENING RELATED TO ASBESTOS}

Two medical students, who had had no previous experience in chest radiography related to asbestos were trained to measure pleural thickness for this study. They measured all films independently. The films that were given different values by the two readers were reviewed together so that the readers reached an agreement. The instruction to the students was to measure the maximum width of the shadow (not muscle) found in the lateral thoracic part around the sixth to the 10th costae in units of $0.5 \mathrm{~mm}$ separately for both the right and left sides.

Films were rearranged at random regardless of the year and order, and information such as the year and subject name were blinded.
Table 2 The maximum width of the pleura in 1978 and 1990

\begin{tabular}{|c|c|c|c|}
\hline Year & $\begin{array}{l}\text { Non-smokers } \\
(n=20) \\
\text { Mean }(S D)\end{array}$ & $\begin{array}{l}\text { Ex-smokers } \\
(n=29) \\
\text { Mean (SD) }\end{array}$ & $\begin{array}{l}\text { Smokers } \\
(n=78) \\
\text { Mean }(S D)\end{array}$ \\
\hline \multicolumn{4}{|c|}{ Right lung } \\
\hline 1978 & $0.65(0.93)$ & $0.90(0 \cdot 88)$ & $0.96(1.01)$ \\
\hline 1990 & $1 \cdot 20(1 \cdot 16)$ & $1.62(1.27)$ & $1.38(1.19)$ \\
\hline \multicolumn{4}{|c|}{ Left lung } \\
\hline 1978 & $0.53(0.68)$ & $0.93(0.87)$ & $0.87(0.96)$ \\
\hline 1990 & $1 \cdot 13(1 \cdot 29)$ & $1 \cdot 47(1 \cdot 13)$ & $1.58(1.35)$ \\
\hline
\end{tabular}

\section{SMOKING HISTORY}

Smoking state was surveyed by a questionnaire during the regular medical check up in April 1990. The subjects without a smoking history were regarded as non-smokers, those who had a smoking history of one year or longer but did not smoke in 1990 as ex-smokers, and those who smoked for 13 years or more including 1990 as current smokers. The Brinkman Index was calculated for the ex- and current smokers based on the number of cigarettes smoked each day and the number of smoking years. The chest $x$ ray films were measured with information on smoking history blinded.

\section{STATISTICAL METHODS}

Smoking history, age, history of asbestos work, and the year when the film was taken were the factors analysed for their effect on pleural thickness, and the right and the left lungs were analysed separately. The effect of smoking state on pleural thickness was examined by considering its main effect on pleural thickness and its interaction with the year that the film was taken. Age and history of asbestos work were included in the analysis as the covariates. The statistical method applied was analysis of variance with the SAS GLM procedure.

\section{Results}

POPULATION CHARACTERISTICS

There was no difference in average age or the number of years of exposure to asbestos among non-smokers, ex-smokers, and current smokers. The mean Brinkman Index of current smokers was significantly higher than that of ex-smokers (table 1).

\section{PLEURAL THICKNESS}

Table 2 shows the mean values of pleural thickness on the right and left sides in the study population classified by smoking state and year of examination. Table 3 gives the results of analysis of variance. Pleural thickness in 1990 was clearly larger than that in 1978. The thickness on both sides tended to be larger in ex- and current-smokers than in non-smokers. This difference by smoking state, 
Table 3 Results of the general linear model (GLM) procedure for factors related to the maximum width of the pleura

\begin{tabular}{|c|c|c|c|c|c|c|c|}
\hline Side & Smoking & Year & $\begin{array}{l}\text { Smoking } \\
x \text { Year }\end{array}$ & Age & $\begin{array}{l}\text { Asbestos } \\
\text { exposure }\end{array}$ & Total & $r^{2}$ \\
\hline \multicolumn{8}{|l|}{ Right: } \\
\hline SS & $2 \cdot 13$ & $14 \cdot 69$ & 1.02 & 1.79 & $1 \cdot 14$ & 26.48 & \\
\hline Variance & 1.06 & $14 \cdot 69$ & 0.51 & 1.79 & $1 \cdot 14$ & $3 \cdot 78$ & \\
\hline$F$ value & 0.90 & $12 \cdot 44^{\star \star \star}$ & 0.43 & 1.52 & 0.96 & $3 \cdot 20^{\star \star \star}$ & 0.084 \\
\hline \multicolumn{8}{|l|}{ Left: } \\
\hline SS & $3 \cdot 86$ & $18 \cdot 12$ & 0.53 & $17 \cdot 11$ & $3 \cdot 17$ & 51.53 & \\
\hline Variance & 1.93 & $18 \cdot 12$ & $0 \cdot 26$ & $17 \cdot 11$ & $3 \cdot 17$ & $7 \cdot 36$ & \\
\hline F value & 1.63 & $15 \cdot 30^{\star \star \star}$ & 0.22 & $14 \cdot 44^{\star \star \star}$ & $2 \cdot 67$ & $6 \cdot 21^{\star \star \star}$ & 0.150 \\
\hline
\end{tabular}

$\star \star \star \mathrm{p}<0.001$.

Smoking, year: main effect; age, asbestos exposure: covariables; smoking $\mathrm{x}$ year: interaction between smoking and year; SS: partial sum of squares (SAS type III SS); Variance: mean square error.

however, was not statistically significant. To avoid the effect of potential instability of the ex-smokers, direct comparison between non-smokers and current smokers excluding the ex-smokers was also performed. Although the mean pleural thickness of the current smokers was consistently larger than that of non-smokers, the difference was not statistically significant. There was no interaction between smoking state and the increase in thickness after 12 years. This finding rejects the possibility of rapid progression of pleural thickening in smokers. The number of years of exposure to asbestos did not significantly affect the pleural thickness. Although a slight difference between the right and left sides in pleural thickening was found, analysis of variance of the combined data on both sides indicated that the difference was not significant. The findings did not change when the continuous variable of the Brinkman index was substituted for the categorical variable of smoking state.

\section{Discussion}

This study was designed to examine whether or not smoking was responsible for chronological changes in pleural thickness, based on evaluations of chest $x$ ray films of asbestos workers taken at an interval of 12 years. As a result, the pleura of workers exposed to asbestos tended to thicken with time and smokers tended to have thicker pleura. The effects of smoking state and the year of examination on pleural thickness were independent, however, and there was no difference in the progression of pleural thickening due to smoking state.

By contrast with the preceding reports on the effect of smoking and exposure to asbestos on pleural change, this study is characterised by the blind evaluation of chest $x$ ray films taken at intervals of 12 years. Furthermore, to improve reliability, pleural thickness was used as an objective index. The measurement was made not by an experienced pulmonary physician but by students specifically trained for this purpose so that no "expert judgment" could be involved. Accordingly, it is unlikely that the results were affected by information bias.

The simple measurement of pleural thickness may introduce an error through the measurement of fatty tissue, which generally increases with age and smoking. Even so, the findings support the negative interaction between smoking and exposure to asbestos in the thickening of the pleura.

By contrast with the decreased possibility of information bias, bias in the selection of subjects cannot be ruled out. In the present study it was impossible to follow up the 343 workers who received the 1978 examination but did not receive the second examination, because of changes in their job, retirement, death etc. These cases might have had attributes different from those of the successful follow up cases for the effects of smoking. Accordingly, because of the restriction of subjects used in this analysis, the results are only applicable to the population defined as male asbestos workers who have been able to work in good health for 12 years.

As regards the possibility of bias affecting the results of this study, a difference in the degree of exposure to asbestos should have been considered, but no such information was available. Although age showed a strong correlation with the years of asbestos exposure and the Brinkman index in smokers, its influence on pleural thickening was not so strong (table 3 ). It is therefore unlikely that age was a confounding factor in this study.

Pleurisy, pleural effusion, and pleural thickening have been thought to occur early among the various lesions related to exposure to asbestos. ${ }^{9}$ As these lesions are highly specific to asbestos, they are important in considering the effects of asbestos on the respiratory organ. It is known that smoking damages the ciliary function of bronchial epithelium and hinders the excretion of intrapulmonary foreign bodies. ${ }^{1011}$ Accordingly, pleural thickening in smokers could be promoted by the higher retention of asbestos fibre. The results of the present study do not support this view. As opposed to lung cancer, which can be caused by smoking without 
asbestos, pleural lesions due to smoking alone are rare. ${ }^{12}$ Lack of interaction between exposure to asbestos and smoking both in mesothelioma and pleural thickening suggests that separate mechanisms act on lung cancer and pleural changes.

We deeply appreciate the assistance of $\mathrm{Mr}$ Tetsuo Yahiro, who was associated with the Industrial Health Center of Saitama at that time. This study was conducted as part of a student seminar at the Department of Public Health, The University of Tokyo (Chairman Professor, Shunichi Araki). It was supported by a Grant in Aid from the Ministry of Education, Science, and Culture.

Requests for reprints to: Eiji Yano, MD, MPH, Teikyo University Research Center for TeikyoHarvard Program, Kaga, Itabashi-ku, Tokyo 173 Japan.

1 Selikoff IJ, Hammond EC, Churg J. Asbestos exposure, smoking, and neoplasia. $\mathcal{F} A M A$ 1968;204:106-12.

2 Elmes PC. Fibrous minerals and health. Fournal of the Geological Society 1980;137:525-35.
3 Weiss W. Cigarette smoke, asbestos and small irregular opacities. Am Rev Respir Dis 1984;130:293-301.

4 Pearle JL. Smoking and duration of asbestos exposure in the production of functional and roentgenographic abnormalities in shipyard workers. 7 Occup Med 1982:24:37-40.

5 Kasuga H, Mikami R, Tamura T, Miyazaki R, Narita N. Effect of smoking on asbestos-related pulmonary and pleural changes. Fpn f Ind Health 1987;29:191-5.

6 Rosenstock L, Barnhart S, Heyer NJ, Pierson DJ, Hudson LD. Pulmonary function and chest $\mathrm{x}$-ray abnormalities in an asbestos exposed cohort. Am Rev Respir Dis 1988;138 272-7.

7 Harries PG, Rossiter CE, Coles RM. Royal naval dockyards asbestos research project. Main morbidity study of the total population at Devonport, Chatham, Portsmouth, and Rosyth dockyards. Alverstoke, Gosport: Institute of Naval Medicine, 1976. (Report No 1 December 1975; CRWP report 1/76.)

8 Andrion A, Pira E, Mollo F. Pleural plaques at autopsy, smoking habits, and asbestos exposure. Eur $f$ Respir Dis 1984;65:125-30.

9 Epler GR, McLoud TC, Gensler EA. Prevalence and incidence of benign asbestos pleural effusion in a working population. $¥ A M A$ 1982;247:61 7-22.

10 Camner $P$. Clearance of particles from the human tracheobronchial tree. Clin Sci 1980;59:79-84.

11 Cohen D, Arai SF, Brain JD. Smoking impairs long-term dust clearance from the lung. Science 1979;204:514-7.

12 Yamada Y, Ebihara I. Pleural thickening like shadows on the chest roentgenogram of non asbestos exposed subjects. F Science of Labour (Rodo Kagaku) 1981;57:25-31. (In Japanese.)

Accepted 4 January 1993 